the first time for a year and a half, having one childthis was twenty-one years ago; she was a widow for three years, whereupon she again married sixteen years ago and had two children-the younger fourteen years ago. Her catamenia lasted from the fourteenth till the forty-eighth year. She said she had overwalked herself when young, and had ovaritis twenty-two years ago. If she walked too much she had pain in the right ovarian region, with heat in the vagina. The bowels acted regularly; there was no vaginal discharge. On vaginal examination her uterus was found to be retroflexed and slightly to the right; the uterine sound showed there was a slight hitch at the inner os. The right ovary was enlarged to the size of a small orange. I saw her again at the ena of January this year. On Feb. 2nd, on vaginal examination, the uterus was still found to be retroflexed, and on being replaced it at once returned to its abnormal position; the cervix was congested, and on the passage of the sound there was some slight bleeding. There was a smail (pin's head) polypus at the os. The tumour of the ovary on the right was rather hard, and it had increased in size. On the 7th I had a consultation with Dr. Cullingworth; he agreed with me that there was a tumour of the right ovary and that it ought to be removed. The operation was performed on the 27th. Dr. Dudley Buxton gave the aristhetic, and Dr. Mary Scharlieb assisted. An incision of about three to four inches was made, and a tumour was found on the right side the size of an orange; it was adherent to the omentum and to the oviduct, and when these were broken down the tumour came away without a pedicle. Just below the tumour was a hydrosalpinx of about the same size; this was brought to the surface. It consisted of the fimbriated end, and the rest of the tube was traced right across the retroverted aterus to the left side of the pelvis, were it was tied and cat away. No appendages were found on the left side, but the right ovary and oviduct were found to be deep down in the pelvis, on the right. The ovary was small (size of a bean), and it and the tabe were removed. The ovarian tumour was a dermoid, and contained cholesterine, hair, and some bony plates. The wound was closed in three layers, and no drainage-tube was used. On March 2Lst the aterus was nearly in its normal position, very slightly to the right. On the 27th the position of the uterus was normal. The interesting points about this case are-(1) the migration of the left ovary over to the right side; (2) the extension of the oviduct across the pelvis, forming a bridle keeping down the fandus of the nterus ; and (3) the rapid atrophy of the other ovary three years only after the menopause. I should be glad to know whether other observers have noticed any such similar migration on the part of an ovary, and to what it may be attributed.

Harley-street, W.

\section{A CASE OF "DYSPHAGIA LUSORIA."}

BY T. H. KELloCK, M.D. CANTAB., F.R.C.S. ENG., MEDICAL SUPERINTENDEYT, HOSPITAL FOR SICK CHILDREN GREAT ORMOND-STREEI';

$$
\triangle A N D
$$

Fredr. E. BatTen, M.B., B.C.Cantab., M.R.C.P. Lond., PATHOLOGIST TO THE HOSPITAL.

THE term "dysphagia lusoria" is used by Fagge 1 in describing a case reported by Dr. Bayford of Lewes in which dysphagia occurred in a child the subject of an abnormal origin and course of the right subclavian artery; Mackenzie ${ }^{2}$ mentions this symptom as occurring in the same connexion; and Prichard ${ }^{3}$ has described a case where a fish-bone stack in such an abnormal artery behind the cesophagus and caused death by hæmorrhage. Referring to Dr. Bayford's case, Fagge suggests that the dyephagia was spasmodic and its occurrence in connexion with the abnormal artery probably only a coincidence; that it may be something more than this we think the following case tends to show.

$A$ healthy boy. aged two years and ten months was brought to the Hospital for Sick Children, Great Ormond-street, on the evening of March 6th, 1894, having been severely choked whilst eating an apple; on this occasion nothing could be found in the pharynx, but the child had been affected seriously enough by the accident to warrant his being kept in the hospital that night. He was, however, discharsed quite

$$
\text { I Fagge's Principles and Practice of Medicine, vol ii., p. } 313 .
$$

well on the following morning. On Oct. 30th he was again bronght hurriedly to the hospital about 2 P.M. with the history that he had been suddenly choked whilst eating his dinner; he was cyanosed and breathing with some difficulty, and whilst in the casualty room became much worse and ceased to breathe altogether; the trachea was opened at once and artificial respiration performed for about half an hour, but without restoring natural breathing. At the post-mortem examination, twenty-one hours after death, a small blood.clot was found in the trachea, which had been opened by division of the fourth, fifth, and sixth rings. A large mass of granular-looking material (probably sausage) was found lying fairly loosely at the back of the pharynx, but it is uncertain whether or not it occluded the upper opening of the larynx. On dissecting the arteries arising from the aorta the following arrangement was found. There was no innominate artery; the two common carotids came off practically together, the left following the usual course, but the right crossing the trachea from the left side just above the sternal notch to reach its usual position on the right side of the neck. The left subclavian came off the arch of the aorta next and followed a normal course ; then came the right subclavian, arising from the descending part of the arch and crossing obliquely behind the cesophagus between this and the spine and behind the right scalenus anticus muscle to its usual situation at the root of the neck, this arrangement of vessels closely resembling that described in Quain's Anatomy and elsewhere as due to the persistence of the right aortic root and the abnormal closure of the fourth right arterial arch, which normally remains patent as the right subclavian artery.

\section{d attirtor}

\section{H OS P I T L P RA C T I E, BRITISH AND FOREIGN.}

Nulla autem est alia pro certo noscendi via, nisi quamplurimas et norborum et dissectionum historias, tum aliorum tum proprias collecta habere, et inter se comparare.-MORGAGNI De Sed. et Caus. Morb. lib. iv. Procemium.

\section{KING'S COLLEGE HOSPITAL}

FOUR CASES OF TUBERCULOUS DISEASE OF THE BLADDER TREATED BY SUPRA.PUBIC CYSTOTOMY; REMARIKS.

(Under the care of Mr. W. WATSON CHEYNE.)

WHEN publishing recently the account of a case of successfal cystotomy for tuberculous disease of the bladder, we commented on the small number of patients who had required this treatment. In doing so we did not mention the first two cases of the following series which had escaped our notice. We now give a short abstract of them, and bring bafore our readers two others which were treated in a similar manner. A curious fact, and one worthy of note, is the sex of these patients, most of the published cases having occurred in women. We agree with $\mathrm{Mr}$. Cheyne in attaching importance to rest as a curative agent in tuberculous disease, but think it better to scrape these ulcerations after the opening of the bladder. Rest alone is not always sufficient to cure tuberculous disease in other parts of the body, yet when the diseased part has been subjected to the action of the curette cure often follows; few would contend, however, that the operation had removed the whole of the disease in the cases which get well after the scraping.

CASE 1. - A man aged thirty-six years consulted Mr. Cheyne in February, 1891. A short time previously he had begun to suffer from frequency of micturition, accompanied by pain towards the end of the act. This had been getting worse, and for the last two days he had been passing urine every two hours; at the end of micturition pure blood was passed, and the pain in his bladder and penis was very gevere. The bladder was very tender, both above the pubis and on examination per rectum. There was no enlargement or tenderness of the prostate or vesicula seminales. The testicles were normal. There was no kidney enlargement or tenderness. The passage of a sound caused great pain. The urine was acid and contained blood and pus. The temperature was 